\title{
Jervell and Lange-Nielsen syndrome
}

INSERM

\section{Source}

INSERM. (1999). Orphanet: an online rare disease and orphan drug data base. Jervell and Lange-Nielsen syndrome. ORPHA:90647

Jervell and Lange-Nielsen syndrome (JLNS) is an autosomal recessive variant of familial long QT syndrome (see this term) characterized by congenital profound bilateral sensorineural hearing loss, a long QT interval on electrocardiogram and ventricular tachyarrhythmias. 